\title{
Internal mammary lymph node biopsy guided by computed tomography
}

\author{
HENRY C. IRVING \\ F.R.C.R.
}

\author{
GRAHAM J. HARDY \\ M.R.C.Path.
}

St James's University Hospital, Leeds LS9 7TF

\section{Summary}

Internal mammary lymph node enlargement may be demonstrated using computed tomography (CT), and a confirmatory tissue diagnosis of metastatic involvement may be obtained using fine needle aspiration biopsy with needle tip placement guided by the CT scanner. A case history is described to illustrate how a patient presented 9 years after mastectomy with an internal mammary lymph node metastasis and how cytopathological diagnosis of this metastasis was achieved by CT guided biopsy.

\section{Introduction}

Carcinoma of the breast may metastasize to the internal mammary lymph nodes but attempts at demonstrating enlargement of these lymph nodes have met with limited success before the introduction of computed tomography (CT). The following case report indicates how internal mammary lymph node metastases may be detected via CT, and how a tissue diagnosis may be obtained using CT-guided fineneedle aspiration biopsy.

\section{Case report}

The patient, a 44-year-old female, presented in 1972 with an asymptomatic breast lump. A right mastectomy was performed for an invasive carcinoma. No tumour was identified in any of the five axillary lymph nodes that were sectioned. The patient made a good recovery and had no further treatment.

She presented again in 1981 complaining of pain localized to the right third costochondral junction. No abnormality could be found on examination, and blood count, ESR, liver function tests and chest Xray were all normal. A CT scan was performed (Fig. 1) and this revealed a small $(1 \mathrm{~cm}$ diameter) soft tissue mass on the inner aspect of the anterior chest wall in the position of the internal mammary lymph node chain. A fine-needle aspiration biopsy of this soft tissue mass was performed, having utilized the CT scanner to locate accurately the site of the skin puncture and to demonstrate the needle tip within the mass (Fig. 2). Cytological examination of the material so obtained revealed malignant cells with appearances compatible with a metastasis from the breast carcinoma (Fig. 3). The patient has been referred for radiotherapy, which will be planned using the CT scan for assistance.

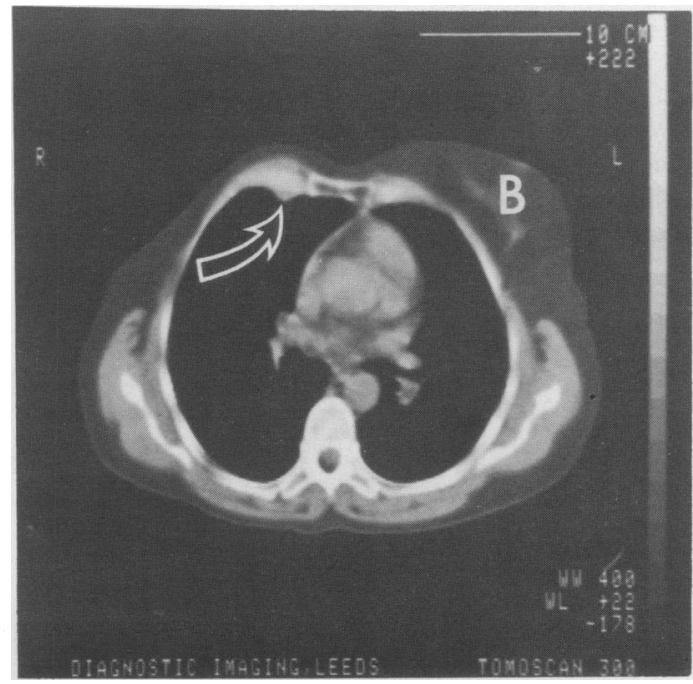

Fig. 1. Section through upper thorax showing normal left breast (B) and a soft tissue mass in the position of the right internal mammary lymph node chain (arrow).

\section{Biopsy method}

CT-guided biopsies of thoracic, abdominal and pelvic lesions are performed at St James's University Hospital on a Philips Tomoscan 300 installation on an out-patient or day-case basis using local anaesthesia.

The skin puncture site is located by obtaining CT scans with opaque tubes placed on the anterior skin surface in a diagonal configuration. When the scan 


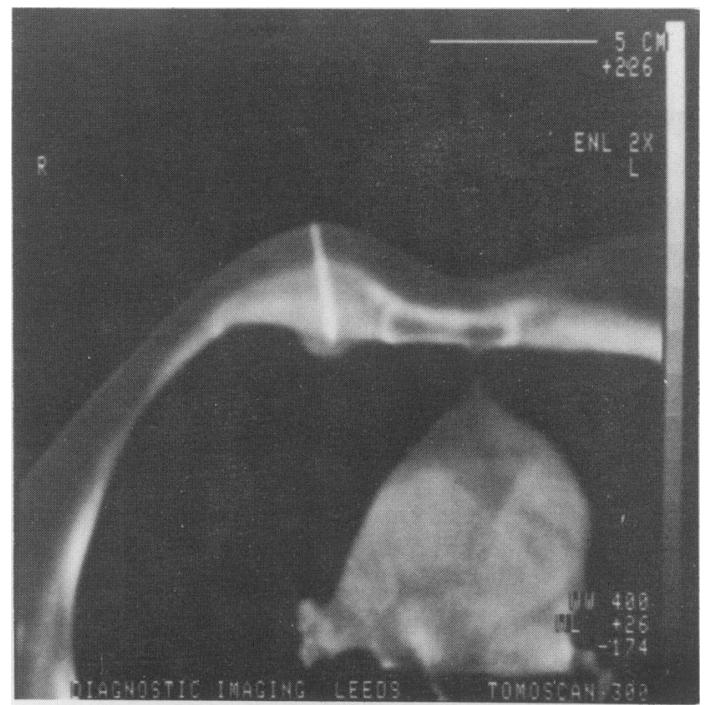

FIG. 2. The needle tip is shown within the internal mammary lymph node.

slice demonstrates the lesion of interest the distance between the two opaque tubes is measured and the exact horizontal level on the patient can then be delineated (Fig. 4). The precise distance from a suitable landmark (e.g. sternal edge) can be mea- sured to locate the site of skin puncture. The fineneedle (22-gauge, short-bevelled, lumbar puncture needle) can then be introduced to a measured depth and a scan be performed to confirm the placement of $\stackrel{5}{9}$ the needle tip within the lesion (Fig. 2). Aspiration of $\bar{g}$ material into the needle is via suction from a $10 \mathrm{ml}$ syringe in association with gentle rotatory and toand-fro movements of the needle. The suction is then released, the needle withdrawn from the patient, and the contents of the needle expelled on to dry microscope slides, smeared and sprayed with fixative. The specimens can then be stained and examined at leisure by the cytologist.

\section{Discussion}

Metastases to internal mammary lymph nodes have been demonstrated at surgery (extended radical mastectomy) in 33\% of patients with carcinoma in the medial or central regions of the breast (Urban and Marjani, 1971). Attempts at demonstrating internal mammary lymph node enlargement by means other than surgery have met with limited success (Pfister, Oh and Ferrucci, 1970; Jemelin and Candarjis, 1973; Chernomordikova et al., 1972; Ege, 1976). CT scans can now provide unique cross-sectional images of the thorax including the soft tissues of the chest wall and this technique has proved to be of value in the detection and management of locally recurrent breas

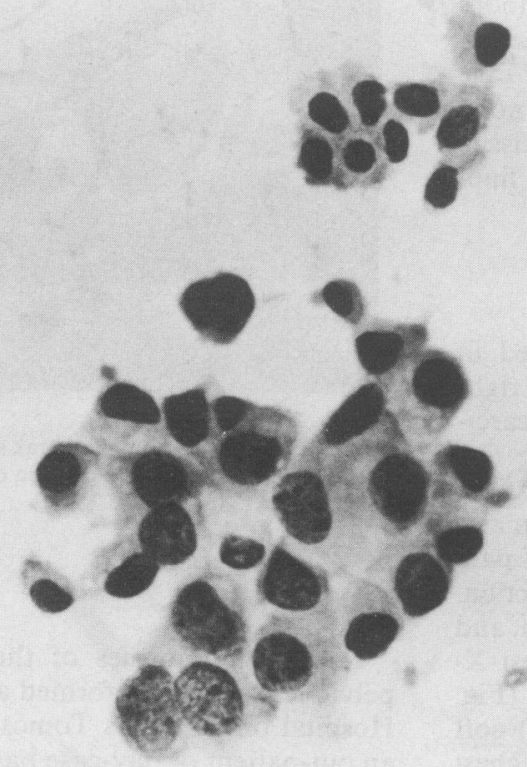

Fig. 3. High power view of carcinoma cells in smear (HE $\times 800)$, 


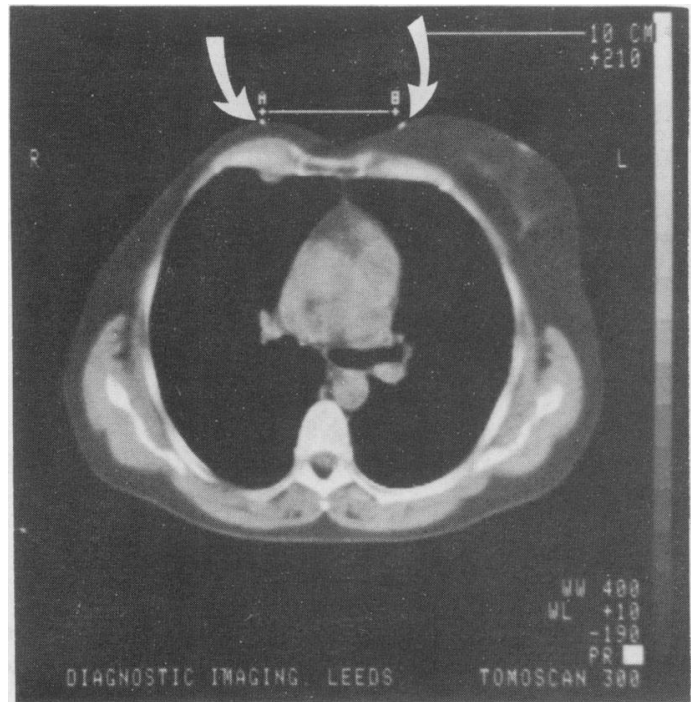

FIG. 4. The opaque tubes on the anterior chest wall are shown (arrows). The diagonal configuration of these tubes is such that measurement of the distance A-B will permit exact skin localization of the section.

cancer (Munzenrider et al., 1979; Gouliamos, Carter and Enami, 1980). The normal internal mammary lymph nodes are not routinely demonstrated on CT examinations, and it has been assumed that a lymph node with a diameter greater than $6 \mathrm{~mm}$ visualized on a CT scan represents malignant lymphadenopathy in patients with known recurrent breast cancer (Meyer and Munzenrider, 1981).

However, the demonstration of a soft tissue mass per se is not a specific diagnosis of malignancy, and when active management such as radiotherapy is to be considered, a tissue diagnosis is desirable. Fineneedle aspiration biopsy techniques have been practised for many years in Scandinavia (Fox, 1979) and elsewhere (Kline and Neal, 1978), and have become more widely accepted since the introduction of the new imaging modalities of ultrasound and CT has permitted the guidance of fine needles into lesions within the thorax, abdomen and pelvis with a high degree of accuracy (Haaga et al., 1977; Ferrucci et al., 1980; Holm, Als and Gammelgaard, 1978; House, 1979).

The complication rate associated with these fineneedle techniques is extremely low. In the case described above, pneumothorax was considered to be a theoretical but extremely remote risk, and care was taken to prevent the needle tip entering the lung. A post-biopsy chest $\mathrm{X}$-ray was obtained before allowing the patient to leave the department. Seeding of tumour cells along the needle-track must also be considered, but the literature now contains documentation of many thousands of cases of fine-needle aspiration biopsy with only two reported instances of needle-tract seeding (Ferrucci et al., 1979; Smith et al., 1980). It is thought these risks are extremely small and may be minimized by good technique (Holm et al., 1978; House, 1979; Ferrucci et al., 1980).

In the case described above, the cytological evidence of recurrent malignancy was considered to be essential because 9 years had elapsed since the original mastectomy and there were no other indicators of recurrent disease. The decision regarding further treatment was thus based solely on the information provided by the CT scan and subsequent guided biopsy.

\section{Acknowledgments}

We wish to thank Dr D. Barnett and Mr D. Walker for referring their patient.

\section{References}

Chernomordikova, M.F., DeEmarsky, L.Y., Kholdin, S.A. \& SELENZNEV, I.K. (1972) Limits and possibilities of transsternal phlebography for detection of metastases in the internal mammary nodes. Radiology, 102, 291.

EGE, G.N. (1976) Internal mammary lymphoscintigraphy. Radio$\log y, 118,101$.

FerrucCi, J.T., Wittenberg, J., Margolies, M.N. \& Carey, R.W. (1979) Malignant seeding of the tract after thin-needle aspiration biopsy. Radiology, 130, 345.

Ferrucci, J.T., Wittenberg, J., Mueller, P.R., Simeone, J.F., HARBIN, W.P. \& KIRKPATRICK, R.H. (1980) Diagnosis of abdominal malignancy by radiologic fine-needle aspiration biopsy. American Journal of Roentgenology, 134, 323.

Fox, C.H. (1979) Innovation in medical diagnosis-The Scandinavian curiosity. Lancet, i, 1387.

Gouliamos, A.D., Carter, B.L. \& Enami, B. (1980) Computed tomography of the chest wall. Radiology, 134, 433.

HaAga, J.R., ReICH, N.E., Havrilla, T.R. \& Alfidi, R.J. (1977) Interventional CT scanning. Radiologic Clinics of North America, XV, 449.

Holm, H.H., Als, O. \& GammelgaARd, J. (1978) Percutaneous aspiration and biopsy procedures under ultrasound visualisation. Clinics in Diagnostic Ultrasound, 1, 137.

HousE, A.J.S. (1979) Biopsy techniques in the investigation of diseases of the lung, mediastinum and chest wall. Radiologic Clinics of North America, XVII, 393.

Jemelin, C. \& CANDARIS, G. (1973) Retrosternal soft tissue: quantitative evaluation and clinical interest. Radiology, $109,7$.

KLINE, T.S. \& NEAL, H.S. (1978) Needle aspiration biopsy: a critical appraisal. Journal of the American Medical Association, 239, 36.

MEYER, J.E. \& MUNZENRIDER, J.E. (1981) Computed tomographic demonstration of internal mammary lymph-node metastasis in patients with locally recurrent breast carcinoma. Radiology, 139, 661.

Munzenrider, J.E., TChakarova, I., Castro, M. \& Carter, B. (1979) Computerized body tomography in breast cancer. Cancer (Philadelphia), 43, 137.

PFISTER, R.C., OH, K.S. \& FERRUCCI, J.T. (1970) Retrosternal density: A radiological evaluation of the retrosternal-premediastinal space. Radiology, 96, 317.

SMITH, F.P., MACDONALD, J.S., SCHEIN, P.S. \& ORNITZ, R.D. (1980) Cutaneous seeding of pancreatic cancer by Skinney-needle aspiration biopsy. Archives of Internal Medicine, 140, 885.

URBAN, J.S. \& MARJANI, M.A. (1971) Significance of internal mammary lymph node metastases in breast cancer. American Journal of Roentgenology, 111, 130. 